\title{
URANUS PHOTOCHEMISTRY AND PROSPECTS FOR VOYAGER 2 AT NEPTUNE
}

\author{
S. K. Atreya \\ Department of Atmospheric, Oceanic and Space Sciences, The University of \\ Michigan, Ann Arbor, MI 48109-2143, U.S.A.
}

ABSTRACT

Methane is the only photochemically active constituent in the atmospheres of Uranus and Neptune. $\mathrm{NH}_{3}, \mathrm{H}_{2} \mathrm{O}$ and $\mathrm{H}_{2} \mathrm{~S}$ are all removed by condensation at pressures greater than 1.5 bars. Although the bulk mole fraction $(\sim 2 \%)$ of $\mathrm{CH}_{4}$ is $20-30$ times its solar value on both planets, it drops to its saturation limit $\left(\sim 10^{-4}\right)$ at the Uranus tropopause, but remains high $(\sim 2 \%)$ at the Neptune tropopause. This results in much greater mixing ratios of the product hydrocarbons (ethane, acetylene, ethylene and polyacetylenes) in the stratosphere of Neptune. On both planets, the photolysis products of methane undergo condensation near the tropopause and the upper stratosphere. Voyager observations of the hydrocarbons at Uranus, and those planned at Neptune will be discussed, along with their implications for the upper atmospheric physics and thermochemistry.

\section{INTRODUCTION}

\begin{abstract}
Although all major planets show a $\mathrm{C} / \mathrm{H}$ ratio that is enhanced relative to solar, it increases progressively from Jupiter to Uranus. On Neptune it is at least comparable to, or somewhat greater than at Uranus. Such a trend in the $\mathrm{C} / \mathrm{H}$ ratio is a reflection of the variation in the ratio of the high $\mathrm{Z}$ (rock and water ice) to low $\mathrm{Z}$ (mainly He and $\mathrm{H}_{2}$ ) material accreted by these planets from the solar nebula /1/. On Uranus and Neptune, the $\mathrm{CH}_{4}$ volume mole fraction is $2 \%$ in the troposphere. It results in the formation of a methane-ice cloud at a pressure of approximately $1300 \mathrm{mb} / 2 /$. The presence of such a cloud on Uranus has been confirmed by Voyager 2 radio refractivity observations $13,4 \%$. Similar observations are planned at Neptune in August, 1989. The condensation of $\mathrm{CH}_{4}$ in the deep troposphere still permits substantial quantities of this constituent in the gas phase, limited by saturation, so that substantial photolysis can occur in the stratosphere. In fact, at the cold-trap temperature of Uranus $(\sim 52 \mathrm{~K})$ the saturated mixing ratio of $\mathrm{CH}_{4}$ is $\sim 10^{-4}$, which results in an optical depth of $\sim 50,000$ at the Lyman-alpha wavelength! Thus the altitude of unit optical depth - where most of the photolysis $\propto c c u r s$ - lies several hundred $\mathrm{km}$ beyond. At the tropopause of Neptune, the $\mathrm{CH}_{4}$ mixing ratio is virtually the same as in its deep troposphere - i.e., it is not limited by saturation. Perhaps convective overshoot of methane ice crystals followed by re-evaporation is responsible. For this to happen, strong vertical mixing in Neptune's troposphere would be needed. Again, the unit optical depth in $\mathrm{CH}_{4}$ would occur high in the atmosphere, actually higher than in the case of Uranus.
\end{abstract}

\section{PHOTOCHEMICAL MODEL}

The reader is referred to chapter 5 in Atreya /2/, Romani /5/, and Atreya, Sandel and Romani /6/ for a comprehensive review of the methane photochemistry, including the relevant rate constants and quantum efficiencies. Here, the main aspects are summarized. The photolysis of $\mathrm{CH}_{4}$ occurs below $1600 \mathrm{~A}$, most of the dissociation $(>92 \%)$, however, is from the absorption of the solar Lyman-alpha photons, producing ${ }^{1} \mathrm{CH}_{2}$ and ${ }^{3} \mathrm{CH}_{2}$ in nearly equal proportion. ${ }^{1} \mathrm{CH}_{2}$ reacts with the background gas, $\mathrm{H}_{2}$, to produce methyl radical, $\mathrm{CH}_{3}$. The reaction of $\mathrm{CH}_{3}$ with itself produces ethane $\left(\mathrm{C}_{2} \mathrm{H}_{6}\right)$ nearly $35 \%$ of the time, it recycles $\mathrm{CH}_{4}$ in the three body reaction with atomic hydrogen nearly $65 \%$ of the time. It also reacts with ${ }^{3} \mathrm{CH}_{2}$ to form $\mathrm{C}_{2} \mathrm{H}_{4}$ (ethyelene). $\mathrm{C}_{2} \mathrm{H}_{4}$ is also produced in the reaction of $\mathrm{CH}_{4}$ with $\mathrm{CH}$ - the latter being one of the photodiss $\propto$ ciation products of $\mathrm{CH}_{4}$. These reactions are summarized below. 
$\begin{array}{rlr}\mathrm{CH}_{4}+\mathrm{h} & \rightarrow{ }^{3} \mathrm{CH}_{2}+2 \mathrm{H} & \mathrm{R} 1 \\ & \rightarrow{ }^{\mathrm{i}} \mathrm{CH}_{2}+\mathrm{H}_{2} & \mathrm{R} 2 \\ & \rightarrow \mathrm{CH}+\mathrm{H}+\mathrm{H}_{2} & \mathrm{R} 3\end{array}$

followed by

$\begin{array}{rl}{ }^{1} \mathrm{CH}_{2}+\mathrm{H}_{2} \rightarrow \mathrm{CH}_{3}+\mathrm{H} & \mathrm{R} 4 \\ \mathrm{CH}_{3}+{ }^{3} \mathrm{CH}_{2} \rightarrow \mathrm{C}_{2} \mathrm{H}_{4}+\mathrm{H} & \text { R5 }\end{array}$

$\mathrm{CH}+\mathrm{CH}_{4} \rightarrow \mathrm{C}_{2} \mathrm{H}_{4}+\mathrm{H} \quad$ R6

and

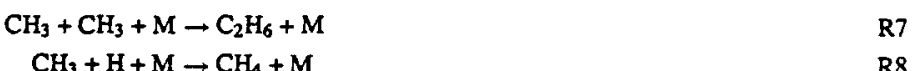

Ethane absorbs solar photons in essentially the same wavelength range as $\mathrm{CH}_{4}$, its destruction is therefore shielded by the latter which has a far greater abundance. Nonetheless, some photolysis of $\mathrm{C}_{2} \mathrm{H}_{6}$ does occur, resulting in the formation of acetylene $\left(\mathrm{C}_{2} \mathrm{H}_{2}\right)$, and $\mathrm{C}_{2} \mathrm{H}_{4}$, i.e.,

$$
\begin{aligned}
\mathrm{C}_{2} \mathrm{H}_{6}+\mathrm{h} \nu & \rightarrow \mathrm{C}_{2} \mathrm{H}_{2}+2 \mathrm{H}_{2} \\
& \rightarrow \mathrm{C}_{2} \mathrm{H}_{4}+\mathrm{H}_{2}
\end{aligned}
$$

Ethylene is dissociated by the solar photons to a far greater wavelength range than $\mathrm{CH}_{4}$ or $\mathrm{C}_{2} \mathrm{H}_{6}$, producing $\mathrm{C}_{2} \mathrm{H}_{2}$, i.e.,

$$
\left.\mathrm{C}_{2} \mathrm{H}_{4}+\mathrm{h} \nu \rightarrow \mathrm{C}_{2} \mathrm{H}_{2}+\mathrm{H}_{2} \text { (or } 2 \mathrm{H}\right)
$$

Acetylene is highly stable in the atmospheres of the major planets. Photolysis of $\mathrm{C}_{2} \mathrm{H}_{2}$ does occur - although with a low quantum yield of products - at longer UV wavelengths $(\lambda>1500 \AA)$.

The result is the eventual formation of various polyacetylenes $\left(\mathrm{C}_{2 n} \mathrm{H}_{2}\right.$, where $\left.n=2,3,4 \ldots\right)$, in the following sequence of reactions

$$
\begin{aligned}
\mathrm{C}_{2} \mathrm{H}_{2}+\mathrm{h} \nu & \rightarrow \mathrm{C}_{2} \mathrm{H}+\mathrm{H} \\
\mathrm{C}_{2} \mathrm{H}+\mathrm{C}_{2} \mathrm{H}_{2} & \rightarrow \mathrm{C}_{4} \mathrm{H}_{2}+\mathrm{H}
\end{aligned}
$$

followed by

$$
\mathrm{C}_{4} \mathrm{H}_{2}+\mathrm{h} \nu \rightarrow \mathrm{C}_{4} \mathrm{H}+\mathrm{H}
$$

$$
\mathrm{C}_{4} \mathrm{H}_{2}+\mathrm{H}+\mathrm{M} \rightarrow \mathrm{C}_{4} \mathrm{H}+\mathrm{H}_{2}+\mathrm{M}
$$

and

$$
\mathrm{C}_{4} \mathrm{H}+\mathrm{C}_{2} \mathrm{H}_{2} \rightarrow \mathrm{C}_{6} \mathrm{H}_{2}+\mathrm{H}_{2}
$$

or

$$
\mathrm{C}_{4} \mathrm{H}+\mathrm{C}_{4} \mathrm{H}_{2} \rightarrow \mathrm{C}_{8} \mathrm{H}_{2}+\mathrm{H}
$$

etc.

The principal loss mechanism for $\mathrm{C}_{2} \mathrm{H}_{2}$ and $\mathrm{C}_{2} \mathrm{H}_{6}$ on Uranus and Neptune is by downward eddy transporn, followed by condensation in the lower stratosphere. The polyacetylenes, on the other hand, condense out in the near vicinity of their production region.

\section{MODEL RESULTS AND MEASUREMENTS}

Figure 1 shows the steady state height distributions of hydrocarbons above the 1-bar level on Uranus, obtained on the basis of a numerical solution to the chemical scheme just discussed. In this procedure, the methane volume mixing ratio is fixed to its saturation value, 
$8 \times 10^{-5}$ at the tropopause $(T=52 \mathrm{~K}, \mathrm{P}=100 \mathrm{mb})$. The $\mathrm{CH}_{4}$ mixing ratio drops $1010^{-5}$ at $\sim 250 \mathrm{~km}, 10^{-6}$ at $\sim 300 \mathrm{~km}, 10^{-7}$ at $\sim 350$ $\mathrm{km}$, and $10^{-7}$ at $\sim 375 \mathrm{~km}$. The form of the eddy diffusion coefficient is taken to be as follows:

$$
\mathrm{K}_{z}=\mathrm{K}_{h}\left(\mathrm{n}_{h} / \mathrm{n}_{z}\right)^{1 / 2}
$$

where subscripts $z$ and $h$ represent altitudes $z$ and the homopause respectively, $\mathrm{K}$ is the eddy diffusion coefficient, and $\mathrm{n}$ is the atmospheric number density. In Fig. 1, $\mathrm{K}_{h}$ is $10^{4} \mathrm{~cm}^{2} \mathrm{~s}^{-1}$, and the homopause is located at an altitude where the atmospheric density is $10^{15} \mathrm{~cm}^{-3}$ $(P=20$ microbar). The Voyager UV solar occultation measurements of absorption by the hydrocarbons in the Uranian upper atmosphere are best simulated by the abovementioned choice of $K$ and the photochemistry model, as is evident in Fig. 2. Although the eddy mixing in the atmosphere of Uranus is sluggish relative to Jupiter $\left(K_{h}=10^{6} \mathrm{~cm}^{2} \mathrm{~s}^{-1} / 2 /\right.$ (Chapter 4) and Saturn $\left(\mathrm{K}_{h} \approx 10^{8} \mathrm{~cm}^{2} \mathrm{~s}^{-1} ; 2 /\right.$ (Chapter 4), it is consistent with the fact that Uranus does not possess a large internal heat source, unlike Jupiter and Saturn, and that the combined energy input to its atmosphere from the Sun and the magnetosphere is relatively small. Lindzen $\pi /$ has argued that the source of eddy mixing lies in the upward propagating gravity waves that break up in the stratosphere; the generation and the energy flux of these waves are presumably related to the strength of intemal heat source. It should be pointed out that on the basis of the detection of a Raman scattered line at $1280 \mathrm{~A}$ by Voyager 2 at Uranus, Yelle et at /8/ have argued that the eddy diffusion coefficient in the $0.5-100 \mathrm{mb}$ region is in the range $100-350 \mathrm{~cm}^{2} \mathrm{~s}^{-1}$. Actually this value is consistent with the extrapolation of $\mathrm{K}$ from the homopause to the $0.5-100 \mathrm{mb}$ region according to equation (1). However, for the Raman emission to escape the atmosphere, the $\mathrm{CH}_{4}$ mixing ratio in the $0.5 \mathrm{mb}$ region would have to be $\leq 10^{-7}$, which is almost a factor of 1000 lower than that used in the above-mentioned photochemical models. Furthermore, the eddy diffusion coefficient would have to be maintained low $\left(100-350 \mathrm{~cm}^{2} \mathrm{~s}^{-1}\right)$ throughout the 'entire' stratosphere, which is also incompatible with the results of the solar occultation analysis. In fact, production, distribution and the densities of the observed aerosols $/ 9 /$, as well as the radiative transfer in the stratosphere $/ 10 /$ require the larger $\mathrm{CH}_{4}$ mixing ratio used in the photochemical models to interpret the solar occultation observations. At the moment, there is no logical solution to this dilemma. Perhaps there are latitudinal differences both in the vertical mixing and the distributions of the hydrocarbons. The solar occultation observations were done near the equator $\left(4^{\circ} \mathrm{S}\right)$ whereas the Raman-Rayleigh reflection data correspond to the subsolar point which was over the south rotation pole of Uranus at the Voyager 2 epoch. In addition to the constraints on the methane abundance in the photochemical regime, the solar occultation experiment also yielded an acetylene mixing ratio of $10^{-8}$ in the upper atmosphere. Since $\mathrm{C}_{2} \mathrm{H}_{2}$ is a photochemical product of $\mathrm{CH}_{4}$, its abundance varies greatly in the atmosphere. A mixing ratio of $10^{-8}$ would occur at an atmospheric pressure of approximately $0.1 \mathrm{mb}$ (Fig. 1).

Neptune, on the other hand, possesses a substantial internal energy source so that it puts out 2 to 3 times the energy it absorbs from the Sun. Based on this similarity of Neptune with Jupiter and Saturn, and comparison of its model hydrocarbon profiles with ground-based data, Romani and Atreya /11/ have suggested a nominal value of $10^{6} \mathrm{~cm}^{2} \mathrm{~s}^{-1}$ for $\mathrm{K}$ at the homopause of Neptune. It is important to note that although this value is preferred, their models with $\mathrm{K}_{h}=10^{7} \mathrm{~cm}^{2} \mathrm{~s}^{-1}$ are virtually indistinguishable from those with $\mathrm{K}_{h}=10^{6}$ $\mathrm{cm}^{2} \mathrm{~s}^{-1}$, within the range of uncertainty of both the model parameters and the available hydrocarbon column abundance measurements. Fig. 3 shows the dependence of the $\mathrm{CH}_{4}$ mixing ratio on the eddy diffusion coefficient. Fig. 4 shows the distribution of $\mathrm{C}_{2} \mathrm{H}_{2}$ and $\mathrm{C}_{2} \mathrm{H}_{6}$ for the nominal case with $\mathrm{K}=10^{6} \mathrm{~cm}^{2} \mathrm{~s}^{-1}$. These photochemical models were calculated for low to mid latitude region (25 $\mathrm{S}$ ) which is close to one of the solar occultation geometries for Voyager 2. Unlike Uranus, ethane has been detected in the infrared at Neptune. Its mixing ratio in the stratosphere is on the order of $6 \times 10^{-6}$ with an uncertainty of a factor of $3 / 12 \%$. Previous measurements of $\mathrm{C}_{2} \mathrm{H}_{6}$ gave values as low as $10^{-6}$. The larger $\mathrm{CH}_{4}$ abundance as well as greater temperature gradient in the stratosphere of Neptune relative to Uranus are most likely responsible for the greater abundance of gas phase $\mathrm{C}_{2} \mathrm{H}_{6}$ on Neptune. Acetylene poses a problem. The IR measurements yield a $\mathrm{C}_{2} \mathrm{H}_{2}$ mixing ratio of $9 \times 10^{-7}$ in the stratosphere $/ 12 /$, which is consistent with the model calculations (Fig. 4). However, from the IUE observations, Caldwell, et al. /13/ have concluded a much smaller $\mathrm{C}_{2} \mathrm{H}_{2}$ mixing ratio of $4 \times 10^{-9}$. There are two possible explanations for this large discrepancy beween the two results. First, the UV measurements correspond to a different atmospheric region (higher) than the $\mathrm{IR}$, which would inevitably have a different $\mathrm{C}_{2} \mathrm{H}_{2}$ mixing ratio (see Fig. 4 , e.g.). Second, the precision with which the reflecied UV sunlight from a small and faint object like Neptune can be measured from the earth orbit is rather low. Note also that the observed ethyelene $\left(\mathrm{C}_{2} \mathrm{H}_{4}\right)$ mixing ratio of $3 \times 10^{-9} / 12 /$ can be explained photochemically only if larger $\left(\sim 10^{-6}\right)$ mixing ratio of $\mathrm{C}_{2} \mathrm{H}_{2}$ existed in the stratosphere $/ 11 \%$. The UV Spectrometer on Voyager 2 will carry out entry and exit solar occultation experiments at latitudes close to the north pole and approximately $50^{\circ} \mathrm{S}$, respectively. The range of spacecraft will be about $5000 \mathrm{~km}$ from the cloud tops, which would permit an excellent height resolution. These experiments are expected to provide useful information on the height profile of $\mathrm{CH}_{4}$, perhaps $\mathrm{C}_{2} \mathrm{H}_{2}$, middle atmospheric temperature structure, and density and temperature distributions in the thermosphere and beyond.

Finally, the height distributions of the hydrocarbons when compared with their saturated mixing ratios (Figs. 1 and 4) show that at some altitude all of them would undergo condensation. Under conditions of equilibrium, this occurs when the partial pressure exceeds the saturation vapor pressure. Thus, at Uranus, condensation commences at atmospheric pressure levels of $0.1 \mathrm{mb}, 2.5 \mathrm{mb}$ and $14 \mathrm{mb}$ for $\mathrm{C}_{4} \mathrm{H}_{2}, \mathrm{C}_{2} \mathrm{H}_{2}$ and $\mathrm{C}_{2} \mathrm{H}_{6}$ respectively (Fig. 1). The corresponding pressure levels are $3.5 \mathrm{mb}(\mathrm{T}=104 \mathrm{~K}), 9 \mathrm{mb}(\mathrm{T}=83 \mathrm{~K})$ and $15 \mathrm{mb}$ $(T=74 \mathrm{~K})$ at Neptune (Fig. 4). Because of uncertainties in the stratospheric thermal structure of Neptune, it is important to recognize that the condensation level is related to the atmospheric temperature rather than atmospheric pressure. Thus, e.g.. should the Voyager measurements give $T=74 \mathrm{~K}$ at $10 \mathrm{mb}$, rather than at $15 \mathrm{mb}$ level, $\mathrm{C}_{2} \mathrm{H}_{6}$ would begin condensing at approximately the $10 \mathrm{mb}$ level also, unlike Fig. 4 where it condenses at the $15 \mathrm{mb}$ level. Following the condensation of the crystals, their growth to a critical size eventually results in their elimination from the atmosphere in the form of snow. Pollack, et al. /9/ have calculated the various time constants to understand the variability of the condensates (haze or aerosol particles). They find that the time constant for transport of 


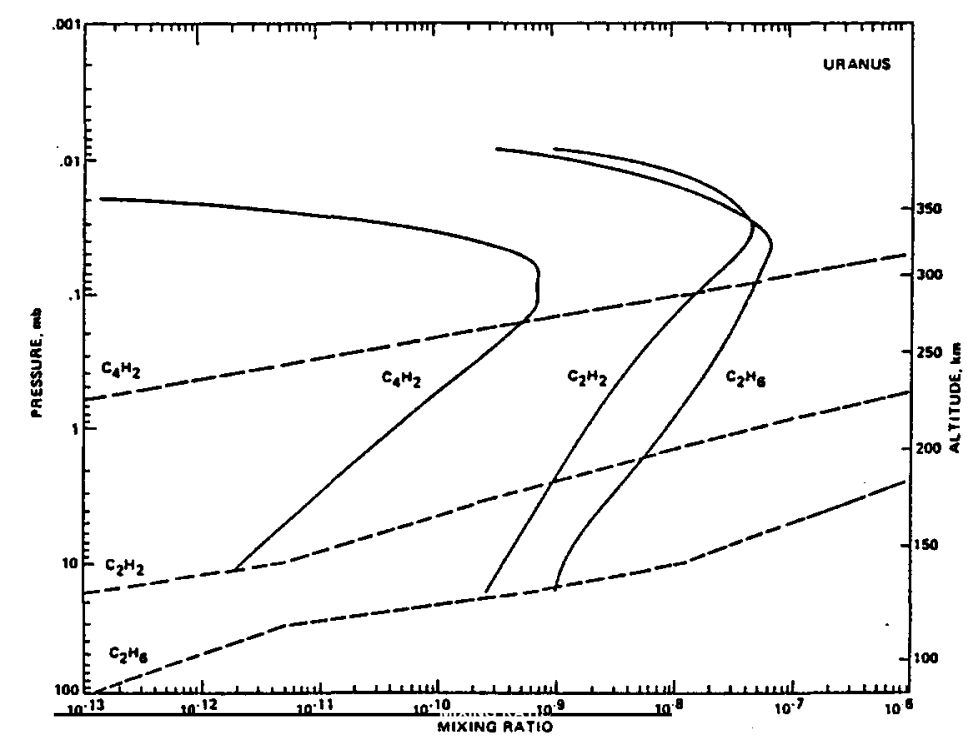

Figure 1. Distributions of the products of $\mathrm{CH}_{4}$ photochemistry on Uranus (solid lines). Altitudes are above the 1-bar pressure level. The saturation vapor mixing ratios are shown by the broken lines. Under conditions of equilibrium, condensation sets in at the level where the solid line curves intersect the broken line curves $19 \%$.

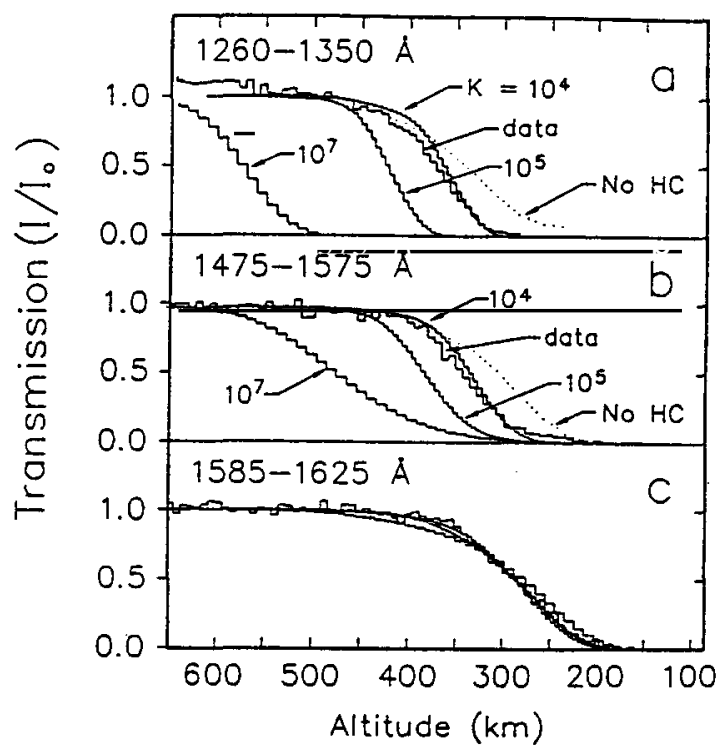

Figure 2. Solar occultation and simulated light curves (with $\mathrm{K}=10^{4}, 10^{5}$ and $10^{7} \mathrm{~cm}^{2} \mathrm{~s}^{-1}$ at the homopause of Uranus). Best fit is with $\mathrm{K}=10^{4} \mathrm{~cm}^{2} \mathrm{~s}^{-1}$ (middle panel, see text). Dotted curves show effect of Rayleigh scattering only. The bottom panel (Rayleigh scattering by $\mathrm{H}_{2}$ ) has the data and 3 simulations falling on top of one another, as expected $/ 14 /$. 


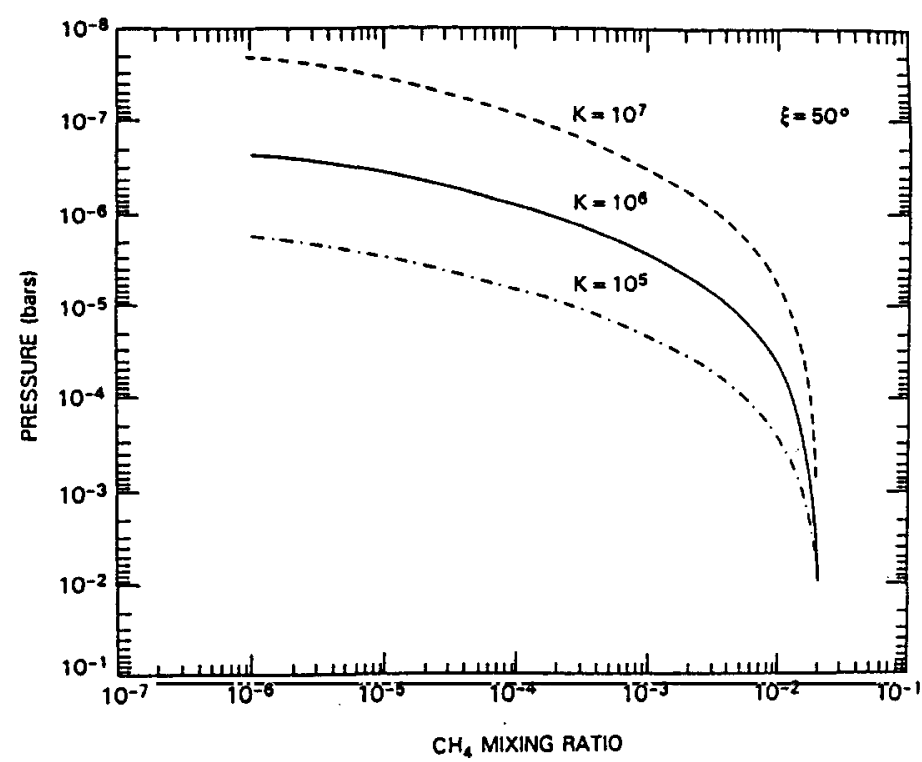

Figure 3. Variation of the $\mathrm{CH}_{4}$ mixing ratio with $\mathrm{K}$ at Neptune. $\mathrm{K} \propto \mathrm{M}^{-0.5}$ is assumed. Solar zenith angle, $\zeta=50^{\circ}$ corresponds to $25^{\circ} \mathrm{S}$ latitude at the time of the Voyager encounter in $1989 / 11 \%$

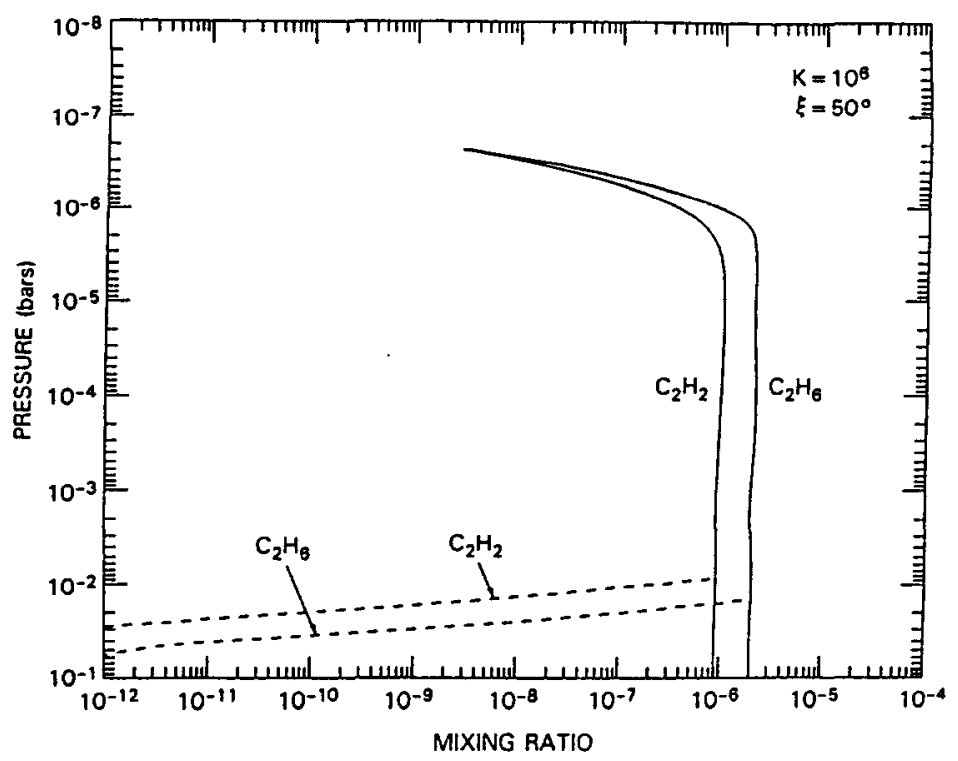

Figure 4. Same as Figure 1, but for Neptune /11\%. 
gases from the region of their production to where they begin to condense $\left(\tau_{e}=H^{2} / \mathrm{K}\right.$, where $\mathrm{H}=$ atmospheric scale height, $\mathrm{K}=$ edtly diffusion coefficient) is of the order of a few hundred years at Uranus. The sedimentation time constant $\left(\tau_{t}=\ell / v_{f}\right.$, where $\ell$ is the distance between condensation and evaporation levels and $\mathrm{v}_{f}$ is the fall velocity) is relatively short, varying from $\sim 1$ yr for $\mathrm{C}_{4} \mathrm{H}_{2}$ at $0.1 \mathrm{mb}$ to $\sim 10$ yr for $\mathrm{C}_{2} \mathrm{H}_{6}$ at $\sim 14 \mathrm{mb}$. Thus, it would seem that eddy diffusion is the principal controlling mechanism for temporal variability of the hazes. The dynamical time constant ( $\tau_{d}=\mathrm{L} / \mathrm{v}$, where $\mathrm{L}$ is the distance travelled and $\mathrm{v}$ is the wind velocity) is also short. For typical East-West winds of $100 \mathrm{~m} \mathrm{~s}^{-1}$. the longitudinal transport around the planet would occur in approximately one week. Transport across regions separated by large latitudes will occur due to meridional $\mathrm{N}-\mathrm{S}$ winds (typically a few $\mathrm{m} \mathrm{s}^{-1}$ ), and it would have a time constant of only a few years, at most. With the orbital period of Uranus of 84 years, then it would seem that there are no latitudinal, longitudinal, or seasonal variations in the haze properies. In reality, however, there are such changes as evidenced from the Voyager 2 narrow angle, high resolution images of the limb of Uranus (Pollack, et al. P). Indeed presence of large circulation cells, as well as changes in the solar insolation with latitude should give rise wo horizontal inhomogeneities as well as seasonal variations in the properties of the hazes.

\section{CONCLUSION}

Despite the relatively cold temperatures prevalent in the middle atmospheres of Uranus and Neptune, sufficient photolysis of $\mathrm{CH}_{4}$ occurs to allow production of $\mathrm{C}_{2} \mathrm{H}_{2}, \mathrm{C}_{2} \mathrm{H}_{6}, \mathrm{C}_{4} \mathrm{H}_{2}$ and at least some of the first order polyacetylenes. The photohcemical products of $\mathrm{CH}_{4}$ undergo condensation in the lower stratosphere. Thus, unlike the earlier notion, the atmospheres of Uranus and Neptune are not "remarkably" clear. In addition to the UV production of the hydrocarbons, likelihood exists of charged particle induced chemistry, both in the gas phase as well as in the condensed phase. Yoyager 2 observations at Neptune in August, 1989, are expected to provide useful data on the height distributions of the hydrocarbons in the gaseous and condensed states. The relevant observations will come from UVS (gaseous hydrocarbons, vertical mixing, upper stratospheric temperature structure), IR (thermal structure), Radio (thermal structure, CH4 cloud level and $\mathrm{CH}_{4}$ mole fraction), photopolarimeter (hazes) and imaging (hazes) experiments.

\section{ACKNOWLEDGMENTS}

This research was supported by a grant from the Planetary Atmospheres Program, NASA Solar System Exploration Division.

\section{REFERENCES}

1. J.B. Pollack and P. Bodenheimer, Theories of the Origin and Evolution of the Giant Planets, in: Origin and Evolution of Planetary Atmospheres, (S.K. Atreya and J.B. Pollack, eds.) Univ. Arizona Press, Tucson, (1988), in press

2. S.K. Atreya, Atmospheres and Ionospheres of the Outer Planets and their Satellites, Springer Verlag, New York and Heidelberg, (1986)

3. G.L. Tyler, D.N. Sweetnam, J.D. Anderson, J.K. Campbell, V.R. Eshleman, D.P. Hinson, G.S. Levy, G.F. Lindel, E. A. Marouf, and R.A. Simpson, Voyager 2 Radio Science Observations of the Uranian System: Atmospheres, Rings, Satellites, Science, 233, 79 (1986)

4. G.F. Lindal, J.R. Lyons, D.M. Sweetnam, V.R. Eshleman, D.P. Hinson, and G.L. Tyler, The Atmosphere of Uranus: Results of Radio Occultation Measurements, J. Geophys, Res., 92, 14 (1987)

5. P.N. Romani, Clouds and Methane Photochemical Hazes on the Outer Planets, Ph.D. Dissertation, University of Michigan, Ann Arbor, (1986)

6. S.K. Atreya, B.R. Sandel, P.N. Romani, Photochemistry and Vertical Mixing, a chapter in Uranus (J.T. Bergstralh, editor), University of Arizona Press, (1989)

7. R.S. Lindzen, Tides and Gravity in the Upper Atmosphere, in: Mesospheric Models and Related Experiments, ed. G. Fiocco, Dordrecht-Holland, Reidel, (1971), p. 122

8. R.V. Yelle, J.C. McConnell, B.R. Sandel, and A.L. Broadfoot, The Dependence of Electroglow on the Solar Flux, J. Geophys. Res., 92, 15110 (1987) 
9. J.B. Pollack, K. Rages, S. Pope, M. Tomasko, P.N. Romani, and S.K. Atreya Nature of the Stratospheric Haze on Uranus: Evidence for Condensed Hydrocarbons, J. Geophys. Res., 92, 15037 (1987)

10. J.F. Appleby, Radiative-Convective Equilibrium Models of Uranus and Neptune, Icarus, 65, 383 (1986)

11. P.N. Romani and S.K. Atreya, Methane Photochemistry and Haze Production on Neptune, Icarus, in press (1988)

12. G.G.Orton, D.K. Aitken, C. Smith, P.F. Roche, J. Caldwell, and R. Snyder, The Spectra of Uranus and Neptune at 8-14 and 17-23 micron, Icarus, 70, 1-12 (1987)

13. J.C. Caldwell, R. Wagener, and K.H. Fricke, Observations of Neptune and Uranus Below 2000 Angstroms with the IUE, Icarus 74,133 (1988)

14. F. Herbert, B.R. Sandel, R.V. Yelle, J.B. Holberg, A.L. Broadfoot, and D.E. Shemansky, The Upper Atmosphere of Uranus: EUV Occultations Observed by Voyager 2, J. Geophys. Res., 92, 15093 (1987) 